The switchboard mechanism

How social media connected citizens during the 2013 floods in Dresden

Albris, Kristoffer

Published in:

Journal of Contingencies and Crisis Management

DOI:

10.1111/1468-5973.12201

Publication date:

2018

Citation for published version (APA):

Albris, K. (2018). The switchboard mechanism: How social media connected citizens during the 2013 floods in Dresden. Journal of Contingencies and Crisis Management, 26(3), 350-357. https://doi.org/10.1111/14685973.12201 


\title{
The Switchboard Mechanism: How Social Media Connected Citi- zens during the 2013 Floods in Dresden
}

Kristoffer Albris

Department of Anthropology, University of Copenhagen

Changing Disasters Research Programme

\begin{abstract}
Social media platforms are increasingly being used for a variety of purposes in disaster preparedness, response and relief work. In a growing number of cases, citizens use social media platforms to self-organize and carry out tasks in emergencies. During the 2013 floods in Dresden, Germany, several Facebook groups emerged as a primary medium for citizens to gather and share information about the emergency. Importantly, the Facebook groups became a way to organize response efforts on the ground. These networks functioned as 'switchboards' whereby citizens in need of help could be connected to those that offered it. The online activity moreover helped to amplify solidarity and social cohesion both towards flood victims, and among volunteers. The article provides an in-depth analysis of one of the Facebook groups by categorizing the different posts according to their function. In line with current research on the topic, the article concludes that social media facilitate new ways for citizens to organize disaster response efforts, and that in Dresden, this was most evident in terms of such a 'switchboard function' that social media provided for citizens.
\end{abstract}

Keywords: Facebook, disaster response, volunteers, self-organization, emergencies

\section{Introduction}

In early June 2013, continuous weeks of rain over Central Europe caused severe floods in the major river catchments of the Elbe and Danube rivers. Widespread civil engagement to participate in flood response activities emerged across the region. Flood events in the region are not new, nor are citizen-driven flood response efforts. What made this event stand out from past events, was how social media platforms was used in the coordination of volunteer response activities.

On June 2, a young man named Daniel Neumann started a Facebook group called Fluthilfe Dresden (Flood Help Dresden) as the Elbe River was about to flood parts of the city. At first, Daniel did not think the group would attract much attention. But by the end of the first day, the group had 12.000 followers. By the end of 
the third day of the emergency, the group peaked at over 50.000 followers. Suddenly he found himself posting messages on Facebook that guided thousands of people to where help was needed. With the help of such Facebook groups, as well as interactive Google Maps and Twitter tags, citizens shared information about the floods and organized response and preparedness activities. After the floods receded, the lesson has been, that social media has changed something profoundly about flood response Dresden.

This article contributes to growing interest in how social media platforms and digital technologies are put to use by citizens, state entities, NGOs, and international organizations in crisis, emergency and disaster response (Alexander, 2014; Crowe, 2012; Hughes and Tapia 2015; Meier, 2015; Starbird and Palen 2011). As much of this research has shown, social media platforms and other digital technologies are beginning to change how ordinary people coordinate and organize collective response efforts to counter the threat of natural hazards.

The article examines the Dresden 2013 floods case as an example of how social media technologies are changing not only how information is circulated in disasters, but also how citizens organize and carry out disaster emergency response activities. The article thus attempts to make a contribution in relation to the existing literature on social media and disasters, by examining how online activity relates to activity 'on the ground'. It does so by combining an ethnographic perspective of volunteer activity with a case study analysis of online activity on a Facebook group during the Dresden floods. The article focuses on one key function of the Facebook group, in which the group acted as a switchboard that connected flood victims and volunteers. The research question that the article thus seeks to answer is how can such online groups and networks do to enhance citizen-driven response efforts?

The article is structured as follows. First, a short overview of the relevant research on social media and self-organized response in disasters is presented. This is followed by a section that explains the methodology. In the next section, responses to the 2013 floods in Dresden are analyzed by focusing on how citizens organized response efforts with the aid of social media platforms. Then follows a section that analyses the patterns of user activity on the already mentioned Facebook group called Fluthilfe Dresden. The article concludes by discussing the key findings from the article in relation broader trends in the research literature.

\section{Social Media and Emergent Disaster Response}

In recent years, we have witnessed a substantial proliferation in the way social media, crowdsourced platforms, and digital mapping technologies are used in emergencies. Services such as 'Google Person Finder' and 'Facebook Safety Check' have helped people locate missing family members (Tabuchi, 2011). Disaster relief operations also benefit from donations channelled through social media and text- 
messaging services (Lobb et al., 2012). Social media platforms can also as Hjorth et, al. (2011) provide new arenas for psychological support and affective cultures to arise following crises and catastrophes. Social media can enhance public awareness when emergencies escalate, as information spreads through online social networks at a more rapid pace and in a more dynamic manner than through traditional media platforms, targeting a broader range of social groups, especially younger age groups (Veil et al., 2011:112; Vultee and Vultee, 2011). Yet there are also concerns that the multiplication of information flows risks more inaccurate and false information being spread (Alexander 2014:725).

More generally, we can say that the rise of social media is transforming the roles of various actors in disaster response and relief, especially the roles of 'ordinary people' or non-affiliated volunteers), who are most often seen by authorities and professionals as either victims, bystanders or onlookers in disaster situations, thus being excluded from response plans and policies (Scanlon et al., 2014). However, the long-standing research tradition on emergent behaviour in disasters (Dynes 1970; Fritz and Williams 1957; Rodriguez et al. 2006) makes it clear that citizens in most cases will volunteer to fill sandbags for contingency floodwalls or shelter homeless flood victims regardless of whether or not this is facilitated through social media. As a consequence, the impact of social media in emergent self-organized response should be weighed against the regularity at which this phenomenon occurs. The argument proposed in this article is rather that social media platforms can thus reshape how affiliated, non-affiliated and first-responder movements are formed, organized, and how they dynamically evolve over the course of an emergency.

Although disaster scholar David Alexander remarks in a recent comprehensive review, that the current research literature on social media use in disasters and emergencies "is still quite limited" (2014:719), the field is rapidly growing, and are reporting on events from Haiti, to California, and to Japan (Stirratt 2011; Sutton et al. 2008; Yates and Paquette 2011). Researchers that study the topic come from different disciplines, and employ different theoretical frameworks and methodological approaches. A dominant approach has been that of crisis informatics, that, as Hughes and Tapia explain, looks at "the information flows and exchanges surrounding crisis events" and how such new forms of communication "affect the social structures, processes, and interactions that underlie them. (2015:681). Much of this research focuses on what Starbird and Palen (2011) call "the information space" or in "microblogging environments". In other words, networks and spaces that operate in the virtual realm.

This article does not focus on trans-local digital volunteer networks, that are often based on crowdsourcing, microblogging, or micromapping environments. Nor does it focus on the kind of digital humanitarian institutions and organizations that are beginning to emerge and become consolidated actors, such as the Digital Humanitarian Network, which connects groups and networks that deal with digital 
crisis communication and information management. Rather, the focus is here on emergent digital networks and groups that are, firstly, locally oriented, and second, do not develop and form into stabilized and consolidated institutions, but are only active when an emergency presents itself. The focus moreover is directed at the transformation that happens between online activity and concrete response work 'on the ground', that is, 'in the physical world'.

One of the main challenges in how to incorporate citizen-driven initiatives into more formalized and official response structures, however, is that that there is a gap between weak management structures that have a strong citizen participation, and a strong management structures that in turn have a lesser degree of citizen involvement (Boersma et al., 2014:1). Importantly, as David Alexander notes, calls for collaborative emergency efforts will elicit stronger responses on social media driven by citizens themselves (Alexander, 2014:721), and, it could be argued, in ways that any government-driven coordination efforts on social media could not copy or mimic. This is perhaps due to the fact that these networks are able to create a mode of interaction where citizens respond sympathetically to other citizens because there is a sense of common purpose and unity, not least in opposition to government authorities.

In a recent outline of the problems involved in putting social media to use in emergencies, Hughes and Tapia have argued for a turn to studying the spaces inbetween digital volunteers and professional responders (2015:682), that also focus on the role of administrators of online platforms as mediators between wide scale public participation in emergencies, and professional agencies. This article follows the line of inquiry, asking what kinds of functions such groups can have as interfaces that mediate a specific demand and supply between those that need help, and those that offer it. It does so by paying attention to the translation processes that occur between social media administrators, online users and volunteers, and the relationship that such online groups have with professional responders.

\section{Methodology}

The article is divided into two analytical sections that draw upon different bodies of empirical data material. The first section describes what occurred during the floods, and examines the different discussions that have surfaced in their wake regarding what role social media ought to have during future events. This part draws upon data material from an ethnographic fieldwork conducted from 2014 to 2016 in Dresden, as part of the author's doctoral research. The data consists of field notes taken during public events, local meetings, and everyday encounters with residents of Dresden. This is supported by around 35 formal semi-structured interviews with flood affected citizens, flood response volunteers, shop owners, as well as with representatives from government entities, NGOs, community associations, grassroots 
initiatives, and administrators of social media platforms. The interviews had a duration of between one and three hours. Recorded interviews were transcribed and translated from German into English. All field notes and interviews have subsequently been coded in Nvivo, a qualitative data analysis software.

The second section of the analysis examines the previously mentioned Facebook group Fluthilfe Dresden in detail. Building upon the context provided in the first analytical section, this section examines the patterns, mechanics, and dynamics of volunteer online activity during the flood event. For this analysis, a mixed quantitative-qualitative methodological approach was used. All the posts made on the group's Facebook page between June 2 and June 9 were plotted into a spreadsheet. These dates were chosen as the period of the emergency response phase before the recovery and reconstruction phases commenced. All posts were then listed chronologically according to date and time, and the number of likes, comments, and shares that each post received were noted down. Finally, the posts were sorted into five different categories that were formulated inductively, i.e. based on the post data itself: 1) networking posts, 2) reporting posts, 3) supplying posts, 4) requesting posts, and 5) building posts. The different categories were then compared in relation to total number, likes, comments, and shares. Further details on the methodological considerations and functions of each post category will be presented later in the article.

In the following, an overview of the emergent civil response activities during the 2013 floods in Dresden through social media based on the author's ethnographic research will be unfolded.

\section{Social Media and the Dresden Floods}

Dresden is a riverine city, founded and built along the banks of the Elbe. For centuries, the city has experienced regular flood events when heavy rain in the catchment region has resulted in inundation from the Elbe and its tributary rivers (Fügner, 1995). Floods are an intrinsic part of Dresden's history. However, the social awareness of flood risk, however, suffered a generational memory gap as no major flood event occurred in the Dresden area between 1941 and 2002, which meant that generations of Dresdners had never experienced first-hand, what a flooded Elbe River looked like when the record-breaking 2002 floods engulfed many parts the city, and large parts of Central Europe. The impact was massive. Much of the structural protection measures had not been properly maintained or upgraded to fend off the water masses. Many people, moreover, had not prepared their individual houses for a likely flood event either, which resulted in the flooding of homes and widespread damages to property. But the flood response efforts were also extensive. Today, the event is remembered as a period of immense solidarity and altruism, as citizens from all over the country converged on Dresden and other 
cities along the Elbe and Danube rivers who had been inundated by the floods. Such was the case again in 2013 when the Elbe almost reached the same level as in 2002.

The 2002 event was much larger and more damaging, not least because the city's structural defenses were in poor shape. When the Elbe River threatened the city again in 2013, both the structural defenses and the collective social awareness of the citizens made the event less disastrous. One of the major differences in the way the response efforts were carried out, however, was that during the June 2013 floods, the citizens of Dresden self-organized through social media platforms in anticipation of the flood risk posed by the Elbe.

It is important to stress that emergent response activities during floods are not a new phenomenon in Dresden. It has not taken the invention of social media for citizens to take an active part in responding to floods by either building provisionary sandbag dikes, providing shelter flood victims or bringing food to other volunteers. Yet the digital revolution has made a significant difference in how people have experienced the 2002 and 2013 events differently. As a study by Kaufhold and Reuter (2016) also reveals, the use of social media during the 2013 floods was widespread across Germany, and different forms of participation and crowdsourcing emerged on both Twitter, Facebook, and Google Maps.

By exchanging pictures and eyewitness accounts on Facebook group pages, citizens actively participated in the management of the emergency. Locals did not only share information, but, importantly, also used the information to locate which areas needed help: filling sandbags, building contingency floodwalls, and preparing food for victims and other volunteers. This was done through the Facebook groups, whereby the administrators of the groups took the role of mediators, that as Hughes and Tapia note, can facilitate communication and collaboration, and can be effective in "advancing conversation and thought around how digital volunteers can fit with emergency response practice" (Hughes and Tapia 2015:691) In this process, the Facebook groups acted as mediating filters that directed the information and chose which information to post that was being fed to the group. This, of course, gave the administrators some degree of power to decide which posts ought to be forwarded and which should not, but it also focused the efforts, and in some respects came to resemble a more professionalized form of chain-of-command execution.

From very early on in the flood emergency, Daniel Neumann received messages from on-the-ground eyewitness accounts, what is often referred to as 'citizen journalists', and posted updates about which areas needed help on the Fluthilfe Dresden page, and also forwarded requests from locals impacted by the floods. Daniel and his team would then direct people towards these areas, and they would also inform people about what kind of help was needed (e.g. sand, bags, transportation, food, shelter, etc.). By turning to the posts on Facebook groups, people who wanted to help could then orient themselves about the current situation, and get a sense of where help was in excess or in demand. Local companies and shops also 
provided resources such as food and drinks for the helpers and posted their offers through the Facebook groups.

In other words, the Facebook groups functioned as switchboards (as in the function of a telephone switchboard) for receiving and directing information between those that needed help and those that wanted to help, while also being the main center for individual citizens, businesses, and even the authorities, to show support for the flood response efforts. In this sense, the social media activity was about much more than just a way of connecting and linking people. The networks also facilitated a space for solidarity to be expressed, where showing sympathy with flood victims and other volunteers became a central function of the networks.

Some reports describe the gathering of large numbers of volunteers taking on an almost carnivalesque character, which is observed in many other instances of disasters (Solnit, 2009). In a few places, improvised bars, food stalls sprung up. Scenes of people passing around everything from chocolate to cigarettes suddenly became part of the event. People worked and hung out on the dikes, passing sandbags and drinks on to each other at a steady pace. Some news reports described an almost euphoric atmosphere in the parks and public spaces along the Elbe (Die Zeit, 2013). The looming disaster emergency had turned into a social spectacle. All of these activities helped to turn the flood response into a matter of much more than merely response, but also a celebration of the unity of civil society. This was amplified through the Facebook groups, and, as will be discussed in the next section of this article, this function or effect of the social media platforms was probably the most significant reason why they have become the subject of a public debate in Dresden in the wake of the floods.

The citizen-driven response efforts that were, in part, mediated and organized through social media platforms both complemented and challenged the professional emergency efforts. In some places, citizens had organized response efforts before the government entities and professional agencies had arrived. The large number of volunteers to some extent enhanced the speed of filling sandbags, and citizens also used their own trucks and cars to transport sand and bags to the temporary filling stations that were set up along the Elbe. Volunteers also arranged for sand and sandbags to be transported to areas that had not received help from official channels. In other cases, there were more people than the response efforts could facilitate, and many that offered to help were asked to leave by the authorities. Some volunteers have reported that they felt redundant in their attempt to help, while others would spend a great deal of time moving up and down the Elbe in search of somewhere where help was in demand.

In a few cases, the large convergence of citizen-volunteers resulted in some poor decisions and problematic solutions. The most well-known example of where the self-organized civilian initiatives got it wrong was at a section of the Leipziger Strasse, a major urban road on the north-eastern side of the Elbe. When people had started to place sandbags along the river, they had also placed a great deal on top of 
the permanent floodwalls where there was supposed to be fitted mobile steel-plate extensions on top. The volunteers did not know this, and the 10.000 sandbags they had placed on top of the wall would have had to be moved again, which the fire department did not eventually do, because it would have taken too much time.

Local authorities and responsible government agencies are now concerned that the future management and orchestration of flood response no longer lie solely in their hands. The Dresden Fire Department sees the massive mobilization of volunteers, in part guided through online networks, as a being indicative of dilettantism and an Erlebniskultur ('a culture of spectacle'). Citizens, on the other hand, have been highly critical of the authorities' ability to act efficiently and quickly, and the purpose of one Facebook group that emerged after the floods was to discuss how the professional agencies failed. Social media administrators have also criticized the local government for not being receptive of the newfound role that online networks have gotten (Grigutsch, 2013).

As a result, the issue has turned into an ongoing public debate taking place in Dresden, concerning what the role of volunteers and social media platforms ought to be in future flood events. Further insights into discussions about the governance of flood emergencies in Dresden can be found elsewhere (Albris, forthcoming; Kuhlicke et al., 2015).

\section{The Switchboard Function}

This section looks more closely at the Facebook group Fluthilfe Dresden. As stated, the rapid increase in followers from a handful of people to over 50.000 in just a couple of days took Daniel Neumann completely by surprise. In this interview excerpt, he explains what happened once the Facebook group started to attract attention:

"I was contacted by a local student club from the university who was interested in helping, and things really picked up speed from then on. By Wednesday night it peaked, and we reached around 50.000 followers. I was amazed. It was a true 'Flächenbrand' [i.e. it went viral]. In those days, I only slept for two hours per night. By Monday evening and onwards, I was receiving about 60 personal Facebook messages and e-mails per minute. It was crazy. I got two of my friends to help me because it was too much to handle. Most of the people who started writing were offering help because they felt they needed to do something. So they offered food, clothes, anything to help. But this quickly became impossible for us to respond to. So I decided that we would only answer those who requested help, not those who offered it. The bread must find the people, and that was what the Facebook page could do. We connected people who needed help with those who offered." (From interview fieldnotes) 
Daniel's group was able to tap into a natural desire for members of the public to offer their help. Other Facebook sites also emerged and became as popular as Fluthilfe Dresden, including Hochwasser Dresden (High Water Dresden) and Elbpegelstand (Elbe Level). But Fluthilfe Dresden has become a public symbol of the impact of digital volunteerism in the flood response in Dresden, and Daniel has appeared in several news articles and interviews (Der Spiegel, 2013; Grigutsch, 2013). In general, the local media in Dresden and the national media of Germany have been highly interested in understanding the phenomenon of what one journalist labeled "flood response 2.0" (Obergassner, 2013).

This section takes a closer look at the posts on the group's wall and compares them in order to analyze what the different functions of the network were during the emergency response phase. They can be divided into five categories according to their intended function: networking, reporting, supplying, requesting and building. The focus in this analysis lies in understanding how the group functioned as a switchboard for forwarding messages coming from the group's followers. All messages appearing on the Fluthilfe Dresden wall are posted by the site administrators, but many of these are links from posts on other Facebook sites, or from other web pages, and the majority are messages that the administrators received from followers and posted on the wall.

A total of 298 posts on the Fluthilfe Dresden wall from the period $2-9$ June 2013, when the flood emergency was most urgent, were plotted into a spreadsheet. ${ }^{1}$ Data about the number of likes, comments, and shares that each post received was then inserted into the spreadsheet. Table 1 provides an overview of the five different post type categories, and the number of likes, comments, and shares that each category received in total. In addition, an average for each posts number of likes, comments, and shares in each category was calculated. Likes are interpreted as being indicative of the number of people supporting a post in a non-committing sense, while comments indicate a desire to engage and participate in a call for a request for help or a discussion. Shares indicate a willingness to expand the reach of the post because the person sharing it feels it should be seen by other people in his or her network. The analysis of these three forms of activity reveals which posts received more or less attention, and thus indicates what the group was used for, and what made it popular among Dresdners.

Table 1. Post types on the Fluthilfe Dresden Facebook Group, and the number of likes, comments, and shares for each post type.

\begin{tabular}{|l|l|r|l|r|r|r|}
\hline Post type & Primary function & $\begin{array}{l}\text { Total } \\
\text { posts }\end{array}$ & Activity & Likes & Comments & Shares \\
\hline \multirow{2}{*}{ Networking } & $\begin{array}{l}\text { Extending and expand- } \\
\text { ing the reach of the net- } \\
\text { work }\end{array}$ & 14 & Total & 764 & 151 & 994 \\
\cline { 3 - 6 } & & Average & 55 & 11 & 71 \\
\hline
\end{tabular}




\begin{tabular}{|l|l|r|l|r|r|r|}
\hline \multirow{2}{*}{ Reporting } & $\begin{array}{l}\text { Forwarding official and } \\
\text { unofficial situational } \\
\text { emergency information }\end{array}$ & 34 & Total & 3458 & 451 & 2665 \\
\cline { 4 - 7 } Supplying & $\begin{array}{l}\text { Actors offering to sup- } \\
\text { ply their help through } \\
\text { group mediators }\end{array}$ & 82 & Average & 102 & 13 & 78 \\
\cline { 4 - 7 } & & Total & 9462 & 546 & 3226 \\
\hline \multirow{2}{*}{ Requesting } & $\begin{array}{l}\text { Citizens requesting help } \\
\text { through group media- } \\
\text { tors }\end{array}$ & 122 & Total & 4506 & 2446 & 6801 \\
\cline { 4 - 7 } Building & $\begin{array}{l}\text { Building a sense of } \\
\text { unity and common pur- } \\
\text { pose. }\end{array}$ & 46 & Average & 37 & 20 & 56 \\
\cline { 4 - 7 } & & & Total & 70670 & 3124 & 14619 \\
\hline
\end{tabular}

The first category, networking posts $(\mathrm{N}=14)$, covers those posts that encourage followers to share either the entire site or specific posts, within their own networks. The intended function of these posts is to build up the network. Logically, many of these posts were circulated at the beginning of the emergency, as the Elbe had not yet reached its peak level.

The second category, reporting posts $(\mathrm{N}=34)$, provide information on the situation of the floods either through eyewitness accounts, government information, or links to news stories by the media.

The third category is supplying posts $(\mathrm{N}=82)$. These cover messages forwarded by the Fluthilfe Dresden administrators from citizens, companies or institutions offering to supply their help, food, resources, shelter, or other things in demand. This category encompasses information being fed to the group administrators and then forwarded so people requesting or needing help could respond. As the emergency developed, Daniel and his team began to change practice, and started forwarding fewer of these offers by people who wanted to help.

Instead, they increased the number of what is here called requesting posts $(\mathrm{N}=122)$. These posts made by the group administrators instructed people where help was needed, what kind of help was needed, and in some cases how to contact those who had requested and called for help through the Fluthilfe Dresden site. These posts increased in number as the emergency progressed. This category encompasses information about where help was needed, and posting it so people offering help could respond. For example, a local in the area of Cossebaude would write to the adminstrators that help was needed to fill sandbags in that area, and then the post on the group's wall would make it possible for people to see where they could go to help.

The fifth and final post type is called building posts $(\mathrm{N}=46)$. This category covers posts with pictures praising the work of volunteers, and in some cases the authorities, by offering feedback about the progress of volunteer work and results that the response efforts had achieved. These posts were often written with highly affective language, typical phrasings being: "Thanks to all volunteers - you are 
amazing!", "Dresden shows the world how it should be done"", or "Show the Elbe who is the boss!".

The data shows that networking posts received relatively few likes and comments on average, but more shares than requesting and supplying posts because these posts asked people to spread the word of the group itself. Reporting posts received a high number of both likes and shares, and a substantial part of these posts (15 out of 34) were messages by different government entities, forwarded by the Fluthilfe Dresden administrators. However, Daniel and his team gradually tried to refrain from using the group to forward too much official information from either local government entities or other actors, and they have subsequently discussed with the administrators of another Facebook group, Elbpegelstand, that the division of labour could potentially be that this other group handles information updates, while Fluthilfe Dresden handles coordination of volunteers, but it remains to be seen how such a scenario would develop.

The data also shows that supplying posts and requesting posts make up the majority of the activity on the group's wall (68\%). As already noted, in the beginning, the majority of posts were supplying, but very early on, Daniel and his team changed strategy and chose to focus more on the requesting posts, which became the most posted category in total. Requesting posts received far more comments than supplying posts, indicative of the fact that when the group administrators posted a message of where help was needed, people would ask follow-up questions about what exactly was needed, and would respond in the affirmative if they intended to respond. However, supplying posts received more likes on average than requesting posts, indicating that people responded sympathetically when someone offered to help.

This tendency to respond positively to signs of solidarity, is most apparent in the final category, building posts. This category received by far the highest amount of both likes, comments, and shares on average. This is also the category in which posts sometimes went viral, i.e. that they became hugely popular and were shared widely beyond the network that followed Fluthilfe Dresden. The most shared post being was that of a man in a wheelchair filling sandbags, which was shared a total of 8.557 times. All the Facebook groups that emerged during the floods were filled with comments by users praising the collective effort by the public in countering the disaster, mirroring the social spectacle that the event also took on the ground in Dresden. The communities of solidarity that arise during disasters events and are formed through online networks also involve people who are potentially far away from the actual disaster context, but who none the less contribute to a public expression of solidarity with those that have suffered from a disaster event. An important observation to make in connection to this, is that these kinds of posts was what made the groups so popular, and not necessarily supplying or requesting posts, that had a more concrete function in the collective response efforts. 
The analysis of this particular Facebook group is not meant to be representative of how such social media networks function in disasters. However, the activities that occurred on this particular Facebook page, does have similarities with other groups that emerged in Dresden, and ones that have emerged in other contexts (Kaufhold and Reuter 2015).

\section{Conclusion}

In conclusion, the case study from Dresden supports the existing research literature by suggesting that we are witnessing a transformation in how ordinary people and professional emergency managers coordinate emergency response efforts in the digital age. Social media platforms enable actors to cooperate and organize emergency response activities more rapidly and across traditional structures of emergency response. This, in itself, is not new (Alexander 2014; Hughes and Tapia 2015), but the case of responses to the Dresden floods, suggests that through switchboard mechanisms as have been described, social media platforms can help distribute the supply of converging volunteer help that is often in excess during emergencies. In this way, there is a practical potential for networks on for instance Facebook groups, to become a mediating actor for the now old problem of integrating 'ordinary people' into emergency plans (Scanlon et al. 2014).

Although, as the case study from Dresden also suggests, there is some degree of political antagonism and blame game following flood events, it is also evident that there were a lot of cooperation between state actors and citizens, both on-theground and in online sphere. In several cases, the social media networks were used to forward and share posts and messages from the Dresden Fire Department, the THW, and the municipal administration. Recently, the local government in Dresden has stated its intents to create an official social media platform that will facilitate citizen involvement during future flood emergencies (Brüggemann, 2016), but it remains to be seen what this platform entails concretely, and whether it will seek to include citizen-driven social media groups, with administrators acting as mediators between citizens and professional responders. It is clear, however, that public information officials involved in communicating with the public (Hughes and Palen 2012), will, also in the case of Dresden, have to change their roles to accommodate the fact, that self-organized citizen-driven initiatives will undoubtedly emerge on social media platforms in the future again.

The findings from this case study suggest that there are indeed potentials for incorporating emergent digital networks into emergency plans, but that there needs to be a stronger involvement and recognition of administrators of for instance Facebook groups on the part of local governments. Moreover, it requires authorities to take seriously that a sense of common purpose, unity, solidarity is driving forces behind people's engagement in responding to collective threats. On the other hand, 
it also requires those people who have emerged as central to emergent online networks, namely administrators, to engage with government agencies and entities, which for Dresden, at least, seems to be the case in future flood events.

Emergent responses from citizens are likely to occur during most disasters, and in this sense, social media platforms could be a binding link between government entities and citizens if there is a willingness on both sides. An exploration of the challenges associated with the rise of social media in emergencies, their consequences, and possible advantages and problems, lies beyond the scope of this paper. More research that addresses these and related issues will undoubtedly surface in the coming years as disaster response continues to feel the impact of the digital revolution. A persistent focus on how emergent groups and activities are mediated and orchestrated through social media and digital technologies needs to be at the center of such research, rather than seeing social media only as a medium for sharing and circulating information. This article has sought to demonstrate that new forms of media can indeed have a far greater impact on disaster response.

\section{Notes}

1. The data from the Facebook group was manually plotted into an Excel spreadsheet in the summer of 2016. As a substantial time had passed the time of the flood in June 2013, the number of likes, comments and shares that posts received have been changed due to shifts in the composition of followers. However, the changes have been minor, and for the present purposes, the data material being analyzed is representative for the group activities during the floods. The Fluthilfe Dresden group is a publicly open Facebook group.

\section{References}

Alexander, D. (2014), 'Social Media in Disaster Risk Reduction and Crisis Management', Science Engineering Ethics, Volume 20, pp. 717-733.

Bankoff, G. (2004), 'Time Is of the Essence: Disasters, Vulnerability, and History', International Journal of Mass Emergencies and Disasters, Volume 22, Number 3 , pp. 23-42.

Bardo, John. (1978), Organization response to Disaster: A Typology of Adaptation and Change, Mass Emergencies, Volume 3, pp. 87-104.

Boersma, F.K., Ferguson, J.E., Groenewegen, P., and Wolbers, J.J. (2014), 'Beyond the myth of control: Toward network switching in disaster management', In S.R. Hiltz, M.S. Pfaff, L. Plotnick, and P.C. Shih, (eds), Proceedings of the 11th International ISCRAM Conference, pp. 123-127. 
Brüggemann, D. (2016), 'Dresden bei Facebook und Twitter in Alarmbereitschaft', MOPO24, 29 April.

https://mopo24.de/nachrichten/dresden-facebook-twitter-alarmbereitschaft-67758 (accessed 31 August 2016).

Crowe, A. (2012), Disasters 2.0: The application of social media systems for modern emergency management, Boca Raton, FL: CRC Press.

Drabek, T.E., and McEntire D.A. (2003), 'Emergent Phenomena and the Sociology of Disaster: Lessons, Trends, and Opportunities from the Research Literature', Disaster Prevention and Management, Volume 12, Number 2, pp. 97-112.

Dufty, N. (2012), 'Using social media to build community disaster resilience', Australian Journal of Emergency Management, Volume 27, Number 1, pp. 40-45.

Dynes, R.R. (1970), Organized Behavior in Disaster, Lexington, MA: Heath Lexington Books.

Fritz, C.E., and Williams, H.B., (1957), "The Human Being in Disasters: A Research Perspective." The Annals of the American Academy of Political and Social Science, Volume 309, pp. 42-51.

Fügner, D. (1995), Hochwasserkatastrophen in Sachsen, Tauchaer Verlag, Taucha.

Grigutsch, H. (2013), 'Gute Ideen und Widersprüche: Initiatoren von "Fluthilfe Dresden" tun sich schwer mit der Kooperation', Dresden Neueste Nachrichten Online, 14 June, http://www.dnn.de/Dresden/Lokales/Gute-Ideen-und-Widersprueche-Initiatorenvon-Fluthilfe-Dresden-tun-sich-schwer-mit-der-Kooperation (accessed 31 August 2016).

Hjorth, L., and Kim, K.H.Y. (2011), 'The mourning after: A case study of social media in the 3.11 earthquake disaster in Japan', Television and New Media, Volume 12, Issue 6, pp. 552-559.

Hughes, A. L., and Palen, L. (2012). The evolving role of the public information officer: An examination of social media in emergency management, Journal of Homeland Security and Emergency Management, Volume 9, Issue 1.

Hughes, A. L. And Tapia, A. H. (2015), Social Media in Crisis: When Professional Responders Meet Digital Volunteers, Journal of Homeland Security and 
Emergency Management, Volume 12, Issue 3, pp. 679-706.

Kaufhold, M., and Reuter, C. (2016), 'The Self-Organization of Digital Volunteers across Social Media: The Case of the 2013 European Floods in Germany', Homeland Security \& Emergency Management, Volume 13, Number 1, pp. 137-166

Kendra, J.M., and Wachtendorf, T. (2003), Creativity in Emergency Response after the World Trade Center Attack. Beyond September 11th: An Account of Post-Disaster Research, Special Publication \#39 Natural Hazards Research and Applications Information Center, University of Colorado, Boulder, CO.

Kuhlicke, C., Callsen, I., and Begg, C. (2015), 'Reputational risks and participation in flood risk management and the public debate about the 2013 floods in Germany', Environmental Science and Policy, Volume 55, pp. 318-325.

Lobb, A., Mock, N., \& Hutchinson, P. L. (2012), 'Traditional and social media coverage and charitable giving following the 2010 earthquake in Haiti', Prehospital and Disaster Medicine, Volume 27, Issue 4, pp. 319-324.

Meier, P. (2015), Digital Humanitarians: How Big Data is Changing the Face of Humanitarian Response, CRC Press, Boca Raton, FL.

Obergassner, P. (2013), 'Fluthilfe 2.0', Stuttgarter Zeitung, 13 June, http://www.stuttgarter-zeitung.de/inhalt.hochwasser-in-sozialen-medien-fluthilfe20.840e2039-1d61-4f12-833a-224e8ed5ad39.html (accessed 31 August 2016).

Rodriquez, H., Trainor, J. and Quarantelli, E.L. (2006), 'Rising to the Challenges of a Catastrophe: The Emergent and Prosocial Behaviour Following Hurricane Katrina'. The Annals of the American Academy of Political and Social Science, Volume 604, pp. 82-101.

Scanlon, J., Helsloot, I., and Groendaal, J. (2014), 'Putting it All Together: Integrating Ordinary People into Emergency Response', International Journal of Mass Emergencies and Disasters, Volume 31, Issue 1, pp. 43-63.

Solnit, R. (2009), A Paradise Built in Hell: The Extraordinary Communities that Arise in Disaster, Viking, New York, NY.

Stirratt, A. A. (2011). Social media use in March 2011 Japanese crisis: Impact on emergency preparedness advocacy. Purdue University, West Lafayette, Indiana: Master of Public Health Dissertation.

Sutton, J., Palen, L., \& Shklovski, I. (2008). Backchannels on the front lines: 
Emergent uses of social media in the 2007 southern California wildfires. In F. Fiedrich \& B. Van de Walle (Eds.), Proceedings of the Fifth International ISCRAM Conference, Washington, DC, May 2008, pp. 1-9.

Der Spiegel (2013), 'Fluthelfer über Facebook gesucht', Der Spiegel, 4 June. http://www.spiegel.de/netzwelt/web/hochwasser-hilfe-ueber-facebook-twitterund-webseiten-a-903706.html (accessed 31 August 2016).

Starbird, K., and Palen, L. (2011), "Voluntweeters": Self-organizing by Digital Volunteers in Times of Crisis. In Proceedings of the SIGCHI Conference on Human Factors in Computing Systems, New York, NY, USA: ACM, pp. 1071-1080.

Tabuchi, H. (2011), 'Quick Action Helps Google Win Friends in Japan', New York Times, 11 July, http://www.nytimes.com/2011/07/11/technology/quick-action-helps-google-winfriends-in-japan.html?_r=0 (accessed 31 August 2016).

Veil, S. R., T. Buehner, and M. J. Palenchar. (2011), 'A Work-In-Process Literature Review: Incorporating Social Media in Risk and Crisis Communication', Journal of Contingencies and Crisis Management, Volume 19, Number 2, pp. 110-122.

Vultee, F. and Vultee, D.M. (2011), 'What We Tweet About When We Tweet About Disasters: The Nature and Sources of Microblog Comments During Emergencies', International Journal of Mass Emergencies and Disasters, Volume 29, Number 3, pp. 221-242.

Yates, D. and Paquette, S. (2011), 'Emergency knowledge management and social media technologies: A case study of the 2010 Haitian earthquake', International Journal of Information Management, Volume 31, Number 1, pp. 6-13.

Die Zeit (2013), 'Hochwasser in Dresden: Partystimmung beim Sandsacksleppen', Die Zeit, 6 June.

http://www.zeit.de/gesellschaft/zeitgeschehen/2013-06/dresden-hochwasser-facebook (accessed 31 August 2016). 